
Comercial -4.0

\title{
SITUACIÓN ACTUAL DEL VIH, A 35 AÑOS DE SU DESCUBRIMIENTO
}

\section{Current situation of HIV 35 years after its discovery}

\author{
De La Torre Erick ${ }^{1, a}$ \\ 1. Investigador del Instituto de Salud Carlos III, España \\ a. Biólogo - Máster en Virología
}

El 20 de mayo de 1983 se identificó oficialmente el VIH, lo cual conllevó a que en el 2008 sean galardonados con el premio Nobel de Medicina los investigadores franceses Luc Montagnier y Françoise Barré-Sinoussi (1). En la actualidad, alrededor de 37 millones de personas en el mundo viven infectados con el VIH, y en el 2017 se detectaron 1,7 millones de nuevas infecciones. Asimismo, casi 22 millones de las personas infectadas reciben tratamiento antirretroviral, pero sin embargo aún se reportan alrededor de 1 millón de muertes al año causadas por el Sida. La incidencia de infecciones por el VIH en el Perú ha ido descendiendo en los últimos años, reportándose en el 2017 menos de 1 infección por cada 10000 habitantes, además se estima que entre 58 000-100 000 personas viven infectadas con el virus y que anualmente se reportan 810 a 2500 casos de muertes relacionadas con el Sida (2).

A pesar del gran avance que se ha dado con la terapia antiretroviral, ésta no es capaz de curar la infección, y hasta la actualidad no existe una vacuna capaz de protegernos contra el VIH. Por lo general, con una pastilla al día (que contiene 3 fármacos) el virus queda bajo control, es indetectable en plasma y no hay prácticamente riesgo de contagio. Aunque los fármacos administrados para el tratamiento de la infección han ayudado enormemente a disminuir las tasas de muerte causadas por el Sida, éstos poseen efectos secundarios que conllevan a la aparición de otras enfermedades en los pacientes, y es por ello el interés de encontrar una cura o una vacuna eficaz, ya que el tratamiento es para toda la vida $(2,3)$. El mayor obstáculo continúa siendo el diagnóstico precoz de la infección, ya que hay diversos estudios que indican que hay un mejor pronóstico si el tratamiento se realiza lo más antes posible. Respecto a las vacunas, la mayor tasa de protección se consiguió en un ensayo clínico en fase 3 del año 2008 (RV144), en donde se logró una eficacia del 31\%. Asimismo, existen actualmente diversos programas o proyectos involucrados en diseñar una vacuna que sea capaz de protegernos de la infección con gran eficacia, aunque parece que aún no está cerca de lograrlo (4).

Las diversas organizaciones mundiales han marcado como objetivo el denominado 90-90-90. Esta estrategia consiste en que el $90 \%$ de personas infectadas con el VIH conozcan su condición, el $90 \%$ de estas personas reciban el tratamiento antirretroviral y que el $90 \%$ de estas últimas mantengan al virus a niveles indetectables. Se deben seguir haciendo muchos esfuerzos para lograr esto a nivel mundial, ya que para el año 2017 tres de cada cuatro personas que vivían con el VIH (75\%) conocían su estado, entre estas personas cuatro de cada cinco (79\%) tenían acceso al tratamiento, de las cuales el $81 \%$ habían logrado la supresión viral (2). 


\section{REFERENCIA BIBLIOGRAFICAS}

1. Barré-Sinoussi $F$, Chermann JC, Rey F, Nugeyre MT, Chamaret S, Gruest J, Dauguet C, Axler-Blin C, Vézinet-Brun F, Rouzioux C, Rozenbaum W, Montagnier L. 1983. Isolation of a T-lymphotropic retrovirus from a patient at risk for acquired immune deficiency syndrome (AIDS). Science; 220(4599):868-71.

https://www.ncbi.nlm.nih.gov/pubmed/6189183

2. UNAIDS DATA 2018- Joint United Nations Programme on HIV/AIDS.

http://www.unaids.org/sites/default/files/media_ asset/unaids-data-2018_en.pdf
3. Coiras $M$, López-Huertas $M R$, Pérez-Olmeda $M$, Alcamí J. Understanding HIV-1 latency provides clues for the eradication of long-term reservoirs. 2009. Nat Rev Microbiol. 7(11):798-812. https://www.ncbi.nlm.nih.gov/pubmed/1983448 0

4. Heger E, Schuetz A, Vasan S. 2018. HIV Vaccine Efficacy Trials: RV144 and Beyond. Adv Exp Med Biol; 1075:3-30.

https://www.ncbi.nlm.nih.gov/pubmed/3003078 7 